\title{
ТУВИНЦЫ КИТАЯ В XXI ВЕКЕ: ВЕХИ ИСТОРИИ И СОВРЕМЕННОЕ СОСТОЯНИЕ
}

\author{
Жанна М. Юиа \\ Институт филологии \\ Сибирского отделения \\ Российской академии наук
}

\section{TUVANS IN 21st CENTURY CHINA: HISTORY AND CONTEMPORARY SITUATION}

\author{
Zhanna M. Yusha \\ Institute of Philology, \\ Siberian branch, \\ Russian Academy of Sciences
}

\begin{abstract}
В статье представлен анализ современного состояния традиционной культуры, хозяйственных занятий, образа жизни и быта всех дисперсных групп тувинцев (горно-таежной и таежно-степной зон), проживающих в Китае; рассмотрены вопросы расселения, самоидентификации, этнического состава, а также сохранности религиозных представлений. Тувинцы Китая - малочисленная этническая группа, проживающая в Алтайском аймаке Или-Казахской области СиньцзянУйгурского автономного района (север КНР), на юге Алтайских гор (Китайского Алтая). Территория проживания образует три «очага»: деревни Ак-Хаба - Ханас
\end{abstract} - Хом (основная часть), деревни Ала-Хаак, Тамыкы и районный центр Кок-Догай (остальные). Также тувинцы проживают городах Хаба, Бурчин, Алтай, Бейтун. Соседствуют с казахами, монголами, дунганами, китайцами.

Китайский Алтай тувинцы считают своей родиной. Самоназвание варьируется: кок-мончак, мончак, алдай дывазы, дыва. Все записаны в паспортах монголами, так их называют в Китае (а также кок-мончаками, мончаками). Численность, по их

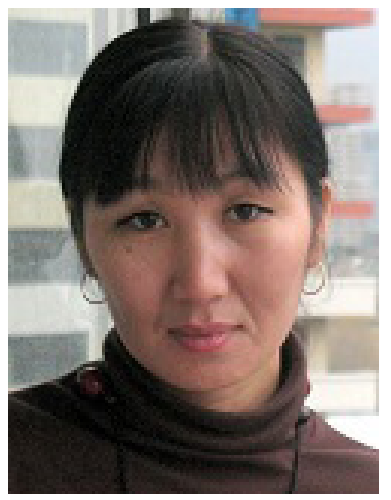

The article analyzes the contemporary situation in culture, economic practices, lifestyle and everyday lives of all disperse groups (in the mountain-taiga and taiga-steppe zones) of Tuvans living in China. We deal with the issues of residential area, self-identification, ethnic structure and the preservation of religious identities within these groups. Chinese Tuvans are a minority ethnic group living in Altay aimak, Ili Kazakh prefecture, Xinjiang Uyghur Autonomous Region, in the south of the Altai mountains (the Chinese Altai). They reside in three clusters, located in the villages of Ak Khaba - Khanas - Khom (majority) and the villages of Ala Khaak, Tamyky and the county seat Koktoqay. Tuvans also live in the towns of Kaba, Burqin, Altay and Beitun, side by side with Kazakhs, Mongols, the Dungan and the Chinese.

Tuvans see the Chinese Altai as their homeland, while the self-appellation can vary: Kok-monchak, Monchak, Aldai dyvazy, the Dyva. Their passport ethnicity is Mongol, which is also what they are called in China (as well as Kok-monchak or

Юша Жанна Монгеевна - кандидат филологических наук, старший научный сотрудник сектора фольклора народов Сибири Института филологии Сибирского отделения Российской академии наук. Адрес: 630090, Россия, г. Новосибирск, ул. Николаева, д. 8. Тел.: +7 (383) 330-14-52. Эл. адрес: zhanna-yusha@yandex.ru

Yusha Zhanna Mongeyevna, Candidate of Philology, Senior Research Fellow, Sector of Folklore of Peoples of Siberia, Institute of Philology, Siberian branch, Russian Academy of Sciences. Postal address: 8 Nikolaev St., 630090 Novosibirsk, Russian Federation. Tel.: +7 (383) 330-14-52. Email: zhanna-yusha@yandex.ru 
собственным подсчетам, - ок. 2500 человек, а вместе с родоплеменной группой оорцаг (танды), идентифицирующих себя монголами, - около 6000 чел. Этнический состав китайских тувинцев состоит из традиционных родоплеменных групп. Автором зафиксированы одиннадцать групп (сөөк), которые имеют мелкие подразделения салаа и могут объединяться в одну большую группу.

По типу хозяйствования подразделяются на две группы: горно-таежная (Ак-Хаба, Ханас, Хом; скотоводство), таежно-степная группа (Ала-Хаак, Кок-Догай и Тамыкы; скотоводство и огородное земледелие). Для обеих групп актуалны сбор растений, ягодный и кедровый промысел, охота (уходит в прошлое из-за запрета на оружие). В религиозной обрядности наблюдается синкретизм традиционных верований: дошаманских, шаманистских и буддийских.

Ханас, Хом и Ак-Хаба сегодня являются одним из популярных туристических (для летнего отдыха) регионов Китая. Туризм помогает китайским тувинцам сохранить этническую идентичность и традиционную культуру (этнокультурный туризм). Но есть опасения, что коммерциализация нарушит традиционную этику.

Китайских тувинцев в цеелом пугает перспектива утраты национальной культуры, родного языка. Причины: сокращение этноса, влияние иноэтничной культуры, ассимиляция, устная форма родного языка и др. Активисты планируют добиться включения китайских тувинцев в список национальностей Китая 57-ым народом.

Источниками для написания статьи стали полевые материалы автора, записанные в ходе комплексных экспедиций 2010-2016 г2.

Ключевые слова: тувинцы Китая; Китай; субэтническая группа; Синьцзян-Уйгурский автономный район; этнический состав; этнокультурный туризм; самоидентификация
Monchak). According to their own estimation, there are about 2500 Chinese Tuvans, or over 6000, if we add a tribal group known as Oortsag (Tandy) who identify as Mongols. Ethnically Chinese Tuvans can be subdivided into a number of tribal groups. We have been able to identify 11 such entities (sø日k) which could be further split into a multitude of salaa or grouped together in one big entity.

According to the prevalent economic strategy, Chinese Tuvan groups fall into two categories: the mountain-taiga group (Ak Khaba, Khanas, Khom - cattle breeding) and the taiga-steppe group (Ala Khaak, Koktoqay and Tamyky - cattle breeding and kitchen gardens). Both groups do plant gathering, picking up berries and pine nuts, while hunting is becoming a thing of the past due to a ban on firearms. Their religious rites present a syncretic mix of traditional pre-Shamanic, Shamanic and Buddhist beliefs.

Khanas, Khom and Ak Khaba have recently become popular centers of summer tourism. Tourism, especially of the ethnocultural type, has helped Chinese Tuvans preserve their ethnic identity and traditional culture. Still, commercialization is often viewed as a threat to traditional ethics.

Among greatest fears of Chinese Tuvans there is a prospect of losing ethnic culture and their mother tongue due to population extinction, the influence of foreign-language culture, assimilation, mainly oral use of native language, and other factors. Local activists campaign for Chinese Tuvans to be included onto the list of ethnic groups of China as the country's 57th recognized ethnicity.

This article is based on the author's field observations during the 2010-2016 expeditions to the areas populated by Chinese Tuvans.

Keywords: Tuvans in China; China; sub-ethnic group; Xinjiang Uyghur Autonomous Region; ethnic structure; ethnocultural tourism; self-identification

\section{Введение}

Тувинцы Китая - малочисленная этническая группа, компактно проживающая в многонациональном Алтайском аймаке Или-Казахской области СиньцзянУйгурского автономного района, расположенного в северной части КНР, на юге Алтайских гор, называемых Китайским Алтаем. Территория проживания тувинцев Или-Казахского аймака граничит на юге - с Россией (Республика Алтай), на западе - с Казахстаном, на востоке - с Монголией (Ховдинский аймак).

В Или-Казахской области, по сравнению с остальной территорией Китая, до сих пор наблюдается низкая плотность населения. По китайским меркам, этот 
район является малонаселенным и экономически не развитым. Административный центр Алтайского аймака располагается в городе Алтай. В настоящее время на территории аймака живут представители семнадцати национальностей: китайцы, дунгане, казахи, кыргызы, монголы, узбеки, уйгуры, урянхайцы, маньчжуры, русские, хуэй и др. Они отличаются друг от друга хозяйственнокультурным типом (земледельческий, кочевой), духовно-материальной культурой, конфессиональной принадлежностью к разным мировым религиям (буддизм, ислам, христианство).

Цель статьи - проанализировать современное состояние традиционной культуры, хозяйственных занятий, образа жизни и быта всех дисперсных групп китайских тувинцев в XXI веке; рассмотреть вопросы расселения, самоидентификации, этнического состава, а также сохранность религиозных представлений.

Источниками для написания статьи выступили полевые материалы автора, записанные в ходе комплексных экспедиций 2010-2016 гг., проведенных в местах проживания тувинцев в Синьцзян-Уйгурском автономном районе ИлиКазахской области Алтайского аймака. Результаты отдельных направлений исследований публиковались нами в разных научных изданиях (Юша, 2013ab, 2014abc, 2016ab; Yusha, 2014, 2016ab). Статья иллюстрирована фотографиями автора, выполненными во время экспедиций.

\section{Места расселения}

Китайские тувинцы компактно расселены в населенных пунктах Ак-Хаба, Ханас, Хом, Кок-Догай, Тамыкы, Ала-Хаак. В этих местностях китайские тувинцы проживают совместно с численно преобладающим казахским населением. Тувинские семьи имеются также в городах районного назначения Хаба, Бурчин, Алтай, Бейтун Алтайского аймака. Территория проживания тувинцев образует три «очага». Основное тувинское население расселено в трех деревнях: Ак-Хаба - Ханас - Хом. В значительном отдалении от этих населенных пунктов, в южной части Алтайского аймака, на границе с Ховдинским аймаком Монголии находятся деревня Тамыкы и районный центр Кок-Догай, где проживают тувинцы.

Некоторая часть тувинского населения, ранее жившая в местностях БуурулДогай и Чингил, в настоящее время утратила родной язык, этническую идентичность, ассимилировалась и считает себя монголами. Как отмечала М.В. Монгуш, «живя длительное время в иноэтничной среде, они постепенно подверглись процессу естественной ассимиляции, в результате которого какая-то часть тувинского населения полностью потеряла свой родной язык и вошла в состав других народов» (Монгуш, 1997: 16). С. М. Абрамзон, исследуя этногенез киргизов Китая, установил, что небольшая группа тувинцев (группа кок-мончак) 
вошла в их состав (Абрамзон, 1961: 121). Кроме этого, отмечаются зафиксированные случаи вхождения иных этносов и в родоплеменной состав китайских тувинцев. По рассказам наших информантов, в начале XX в. из Горного Алтая, спасаясь от советской власти, в Китай перекочевали представители алтайских сеоков, которые ассимилировались с китайскими тувинцами, их потомки не знают алтайского языка, считают себя тувинцами, хотя помнят, что их предки пришли с Алтая.

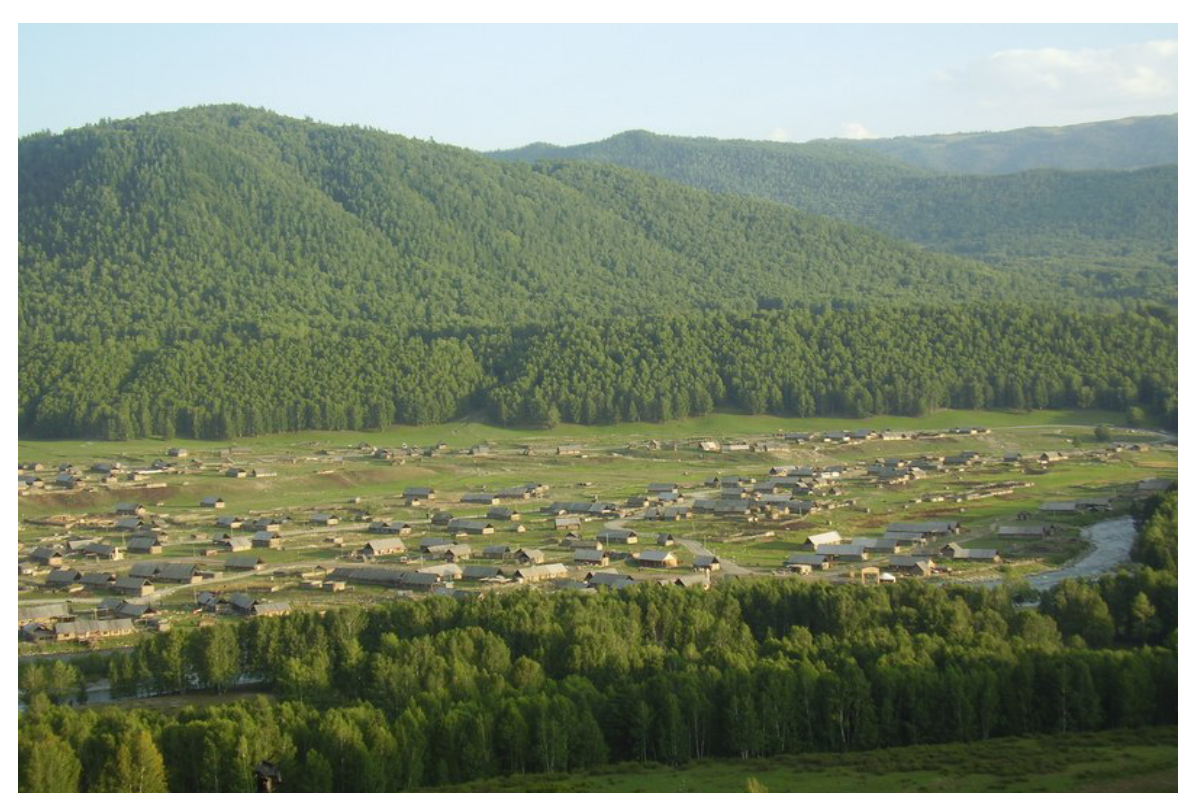

Фото 1. Деревня Хом, где проживает тувинское население (2010 г.).

Photo 1. The village of Khom, where the Tuvan population resides (2010)
Почти до конца XX века район проживания тувинцев был изолирован от остальной территории Китая ввиду отсутствия дорог. По территориальному подразделению, принятому в Китае, уезд (кит. - cun) является самой мелкой единицей районного масштаба. Эта же единица деления называется тувинским словом кыстак. По административному делению деревни-уезды (кыстак) Ханас и Хом подчиняются районному центру городу Бурчин. Деревня-уезд Ак-Хаба имеет подчинение районному центру Хаба. Административным центром деревниуезда Ала-Хаак является город Алтай, деревни-уезда Тамыкы - районный центр Кок-Догай.

Китайский Алтай тувинцы считают своей родиной, здесь издавна кочевали их предки. По устному свидетельству тувинцев, раньше их территория проживания была намного больше, чем сейчас. В конце XIX в. - в 1864 г., когда Казахстан вошел в состав Российской империи, в результате войны тувинцев с русскими войсками южная приграничная часть Китайского Алтая оказалась на территории Казахстана (озера Марга-Хол, Чайсан-Хол, м. Шаңгыштай-Буурел). Эти события подтверждаются историческими материалами. В частности, о проблемах казахского населения, разделенного границей, историк Н. Н. Аблажей пишет: «Демаркизация российско-китайской границы в районе Синьцзяна, осуществленная в 80-х годах XIX в. после присоединения Средней Азии к Российской 
империи, привела, как уже говорилось, к территориальному разделению казахского этноса. Поскольку при установлении границы руководствовались главным образом географическими соображениями, казахское население, проживавшее в приграничье, оказалось фактически разделенным. Наряду с традиционной маятниковой и сезонной миграцией, характерной для кочевого населения, на протяжении двух первых десятилетий XX в. происходили также массовые долговременные перемещения населения» (Аблажей, 2007: 47).

\section{Самоназвание и численность}

Самоназвание китайских тувинцев варьируется: кок-мончак, мончак, алдай дывазы, дыва. Все тувинцы записаны в паспортах монголами, что затрудняет установить их реальное количество. Именно как монголы они входят в число 56 официально признанных национальностей, проживающих на территории КНР. За исключением китайцев-ханьцев, тувинцы, как и другие 55 малочисленных народов, считаются «диаспорными этноменьшинствами» (huaqiao minzu).

Этноним тыва в Китае еще не распространен. Народности Китая тоже называют тувинцев монголами, а также кок-мончаками, мончаками. В научной же литературе они также обозначены под разными названиями: алтайские урянхайцы, кок-мончаки, мончаки, джунгарские тувинцы (Монгуш, 1997, 2002, 2010, 2012: Электр. ресурс; Бавуу-Сюрюн, 2011: Электр. ресурс; Geng Shimin, 2005; Mawkanuli, 2005; Song Zhengchun, 2016).

В настоящее время численность китайских тувинцев, по их собственным подсчетам, составляет около 2500 человек. В это число не входят представители родоплеменной группы оорцаг (иначе танды), идентифицирующие себя монголами, хотя они в совершенстве владеют тувинским языком, соблюдают традиционную обрядность и обычаи, присущие тувинцам. Если прибавить их количество, то китайских тувинцев будет насчитываться около 6000 человек. В материнском этносе тувинцев родоплеменная группа ооржак имеется, но они идентифицируют себя тувинцами. По нашим данным, статистическая таблица состава населения поселковых администраций на 2013 г., где тувинцы записаны в качестве монголов, выглядит следующим образом (см. таб. 1):

Таблица № 1. Современное расселение и численность тувинцев в Китае.

Table 1. The current numbers and residence area of Tuvans in China

\begin{tabular}{|c|c|c|c|c|c|}
\hline $\begin{array}{c}\text { Название } \\
\text { деревни }\end{array}$ & $\begin{array}{c}\text { Монголы- } \\
\text { тувинцы }\end{array}$ & казахи & дунгане & китайцы & $\begin{array}{c}\text { Всего } \\
\text { жителей / } \\
\text { дворов }\end{array}$ \\
\hline Ак-Хаба & 386 & 522 & 0 & 5 & $913 / 125$ \\
\hline Ханас & 752 & 127 & 25 & 1 & $905 / 288$ \\
\hline Хом & 641 & 750 & 18 & 28 & $1439 / 543$ \\
\hline
\end{tabular}


Как видно из представленной таблицы, в названных селах (кроме Ханас) тувинцы преимущественно проживают вместе с казахским населением, в меньшем количестве есть представители монгол, дунган, китайцев. В список не вошло тувинское население Ала-Хаака, где по подсчетам самих тувинцев, насчитывается более 50 тувинских семей. В Тамыкы также имеются более 50 тувинских семей, официально зарегистрованных по месту жительству монголами. Если среди жителей Ак-Хабы, Хом и Ханаса китайцы постоянно не проживают, а в основном, приезжают на заработки в летнее время, то у тувинцев Тамыкы наблюдается большое число местных китайцев.

В последние годы небольшая тувинская группа имеется и в небольших городах административного назначения: Алтай, Хаба, Бурчин. В городе Алтай проживает 10 семей, в Хаба до 2005 года имелось всего 4-5 семей, однако к 2016 г. число тувинских семей увеличилось до 20. Причиной тому явилось то обстоятельство, что монгольскую среднюю школу деревни Ак-Хаба с 7 по 9 класс перенесли в районный центр города Хаба, где преподают учителя тувинской национальности, в связи с чем семьи учителей переехали в город. С 2015 г. монгольскую среднюю школу деревни Хом с 7 по 9 класс перенесли в в административный центр Бурчин.

Этнический состав китайских тувинцев состоит из традиционных родоплеменных групп. Пожилые люди до сих пор знают свою генеалогию до седьмого или девятого колена (поколений). Поскольку родство идет по отцовской линии, обычно при перечислении предыдущих поколений называют имена мужчин, имен сестер не называют, в редких случаях упоминают их количество.

Во время полевых исследований нами зафиксированы следующие одиннадцать тувинских родовых групп (сөөк): хойук, иргит, чаг-тыва, ак-соян, кара-сал, кара-тош, кызыл-соян, хойт, делег, калга, хаа-дарган.

В свою очередь, некоторые тувинские родоплеменные группы у китайских тувинцев подразделяются на более мелкие патронимии (салаа). Сеок хойук подразделяется на такие патронимии: кара-хөйүк; хаа-хөйүк; хөртүгөш-хөйүк; донгак-хөйүк, хүндүгеш-хөйүк, монгуш-хөйүк, хойт хөйүк, шанагаш-хөйүк. Род иркит включает в себя семь подгрупп: улуг иркит, адай иркит (конгуту), шункуур иркит, моол иркит, боос иркит, калчан иркит, ак иркит. Родоплеменная группа чаг-тыва объединяет в себе две группы: сарыг чаг-тыва, кара чаг-тыва. Сеок кара-сал подразделяется на ак-даяак и кок-даяак. Род кызыл-соян имеет две патронимии: толубай и сандык.

В то же время, если в большинстве случаев родовые группы подразделяются на мелкие подразделения, то можно отметить и такой факт, когда несколько родов объединяются в одну родоплеменную группу под одним названием дорт сумун (или мончак), куда входят четыре сеока: хойук, чаг-тыва, иркит, хойт. На- 
звание мончак для других народов служит для обозначения национальной принадлежности всех тувинцев. «Возможно, - пишет М. В. Монгуш, - в свое время из числа всех тувиноязычных групп, проживающих в Синьцзяне, мончаки были наиболее многочисленной группой и по этой причине мончаками стали называть всех тувинцев» (Монгуш, 1997: 11).

По рассказам респондентов, когда один из родов разрастался и между ними существовали правила экзогамии, то после семи поколений проводили необычный шаманский обряд. Он основан на поверии, что после семи-девяти поколений у представителей разных подразделений (салаа) одного сеока происходит смена крови. По этому случаю две патронимии одной родоплеменной группы, имевшие общего предка в семи поколениях, могут провести специальный обряд, с помощью которого прерывали кровную родственную связь между ними. Для проведения этого ритуала шаман выстраивал представителей двух родов в две шеренги, друг против друга. Каждому в руки он давал черный волосяной аркан, который он разрезал на две части. Считали, что после совершенного обряда прерывалась кровная связь, и в будущем они могли между собой заключать браки, обмениваться девушками. Эти представления подтверждаются материалами М. В. Монгуш. «Многие пожилые информаторы утверждали, что обычно после седьмого поколения от общего предка род у них разрастается настолько, что на его основе образуется уже два самостоятельных экзогамных рода, которые в отличие от предыдущих, могут обмениваться невестами» (там же: 42).

До XX в. представители каждой тувинской родоплеменной группы имели определенные места проживания и кочевья, свои охотничьи и пастбищные угодья, которые передавались в наследство по мужской линии. В настоящее время тувинские роды также компактно расселены в местах проживания их предков. Как замечает китайский антрополог Намкамидог, каждый суму-поселение состоит из нескольких родственных групп тувинцев (Namkamidog, 2009). Поскольку при совершении браков соблюдается принцип родовой экзогамии, то в местах проживания определенного рода представителями других родов обычно являются замужние женщины, переехавшие в места проживания супругов.

\section{Религиозные представления}

Согласно мифологическим воззрениям китайских тувинцев, как и у других народов Саяно-Алтайского нагорья, Вселенная состоит из трех миров: Верхнего (Устуу оран), Среднего (Ортаа оран) и Нижнего (Алдыы оран). Верховным божеством Верхнего мира является Курмусту, владыкой Нижнего мира - ЭрликЛовун-хан. Средний мир населен людьми, духами-хозяевами местностей (ээлер), а также различными мифологическими существами, которые могут навредить 
человеку: алмыс, бук, шулмус, чес-тырнак. По представлениям тувинцев, люди Верхнего мира носят свой пояс на уровне подмышек, Среднего мира - на талии, Нижнего - на бедрах.

Существуют представления, что каждый природный объект Среднего мира (река, гора, местность и др.) имеет своего духа-хозяина ээзи, по-другому canmык. При почтительном отношении к ним людей они покровительствовали им, приносили удачу в любых делах. Однако духом-хозяином Китайского Алтая китайские тувинцы считают Ак-Огбена (вариант - Сагаан-Огбен), седобородого старца, ездящего на белом воле. В плане иерархии он выше всех духов-хозяев. Ак-огбен является хозяином всей земли и всего, что находится на ней: природных объектов, скота, зверей. Эти воззрения укладываются в общее традиционное понимание мироустройства всеми другими тюрко-монгольскими народами. Например, «представления о хозяине всего Алтая Алтайдын ээзи сохранились в культуре тюркоязычных алтайцев, которые считали его земным божеством со своими функциями и антропоморфным обликом, хотя имя Алтайдын ээзи постепенно стало заменяться теонимом Алтай Кудай» (Тюхтенева, 2009: 139).

У тувинцев Китая сохраняются пережитки культа почитания окружающего мира. Бытуют представления о том, что каждое живое существо, будь это животное или растение, имеет сагыызын (душу). Подобные взгляды отражают неразрывную взаимосвязь человека и природы, характерную для традиционного мировоззрения тувинцев.

До начала культурной революции (до 1966 г.) у китайских тувинцев повсеместно была развита шаманская традиция, которая имела общие черты с шаманизмом народов Саяно-Алтайского нагорья. Шаман считался посредником между миром людей и миром духов. «При проведении обряда он читает шаманские призывания - алгыштар, которые представляют собой импровизированные поэтические тексты, обращенные к различным духам-хозяевам местностей или к своим духам-помощникам, от которых ожидалась помощь или излечение от болезней» (Юша, 2009: 18). Шаманы участвовали в культовых, лечебных и похоронных обрядах. Следует отметить, что, несмотря на официальный запрет шаманства, люди к ним тайно обращались, и они подпольно проводили некоторые лечебные обряды. Шаманы в народе были уважаемыми людьми, их авторитет был беспрекословным.

Среди китайских тувинцев были знаменитые шаманы, имена и деяния которых сохранились до наших дней: Байанбай-хам, Дакай-хам, Орзугур-хам, Дожу-хам, Харсыга-хам, Домбуш-хам, Шокар-хам, Саандей-хам. Ритуальная одежда шамана полностью соответствовала материнской традиции: ритуальный халат, головный убор. Существовали определенные шаманские атрибуты: бубен (дунгур), колотушка (орба), без которых ни один шаман не имел права 
вести камлание. По воспоминаниям очевидцев, некоторые шаманы могли вести камлание и с помощью варгана (хомус).

В настоящее время шаманская традиция прервана. Последний шаман Орзугур в возрасте 82 лет ушел из жизни в 2001 г. в Ак-Хабе. В памяти народа сохранились в виде нарративов рассказы о шаманах, об их чудесных способностях и силе.

В наши дни тувинцы не перестали совершать многие исконные обряды, основанные на анимистических представлениях. В религиозной обрядности тувинцев также наблюдается синкретизм всех традиционных верований: дошаманских, шаманистских и буддийских.

\section{Хозяйственные занятия}

В настоящее время тувинцы Китая по типу хозяйствования подразделяются на две группы. Первая группа - горно-таежная, которую составляют жители селений Ак-Хаба, Ханас, Хом. Они занимаются скотоводством: держат крупный и мелкий рогатый скот, разводят лошадей. Вторая, таежно-степная группа - это жители Ала-Хаака, Кок-Догая и Тамыкы, они заняты скотоводством и огородным земледелием, как и местные казахи. Эта часть тувинцев выращивает кукурузу, картофель, бобовые культуры, которые переняли от китайцев-земледельцев.

В летне-осенний период для обеих групп немаловажное значение имеет сбор дикорастущих растений, ягодный и кедровый промысел. По примеру китайцев некоторые тувинские семьи начали разводить кур, единичные семьи занимаются пчеловодством (например, в деревне Хом семьи сыновей старика Оокея).

Скотоводство. Для всех этнолокальных тувинских групп основным видом хозяйственной деятельности тувинцев являлось кочевое пастбищное скотоводство с круглогодичным выпасом животных и сезонной сменой кочевий (Октябрьская, 2009: 313). Китайские тувинцы разводят четыре вида скота: коров, лошадей, овец и коз. Как и остальные группы тувинцев, скот делят на две разновидности: с “холодным дыханием” (лошади, козы) и “горячим дыханием” (овцы, коровы). Следуя традиционному способу доения, перед началом дойки к самкам животных подпускают молодняк.

Развитая терминология мастей скота разного вида, а также их наименования по полу и возрасту, богатая скотоводческая лексика свидетельствуют о большой роли скотоводства в хозяйственной жизни китайских тувинцев. Особенно ярко это проявляется в коневодческой лексике: особенности аллюра коней, масти коней, определение возраста лошади по зубам, их половозрастные названия, принадлежности конской упряжи. В фольклорной традиции выращиваемый скот четырех видов прославляется в разных жанрах фольклора. 
$\begin{array}{rcccc}\text { У } & \text { ч } & \text { и } & \text { т } & \text { ы } \\ \text { вая } & & & \text { природно- }\end{array}$

к ли м а т и ески е условия региона, в отличие от российских И Монгольских тувинцев, здесь не держат верблюдов и яковсарлыков. Наибольшее развитие в скотоводстве получило разведение лошадей и крупного рогатого скота, поскольку зимы здесь снежные, осадков выпадает до 2-3 метров, что трудно для содержания большего количества мелко-

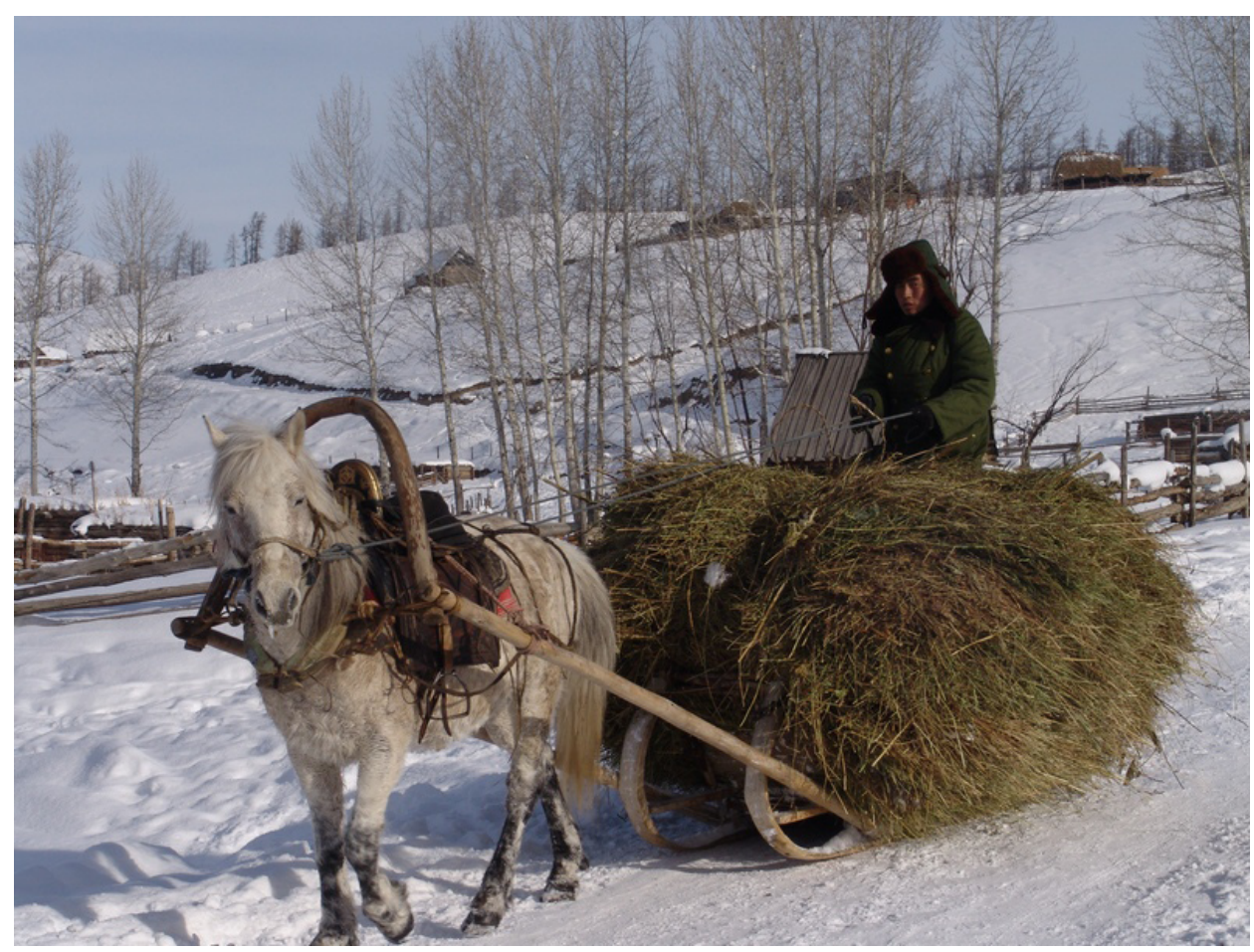

Фото 2. Заготовленное сено используется зимой. В селениях тувинцев часто можно увидеть подобную картину (2010 г.). Photo 2. Hay is made in the summer and used during winter. Scenes like this are typical for Tuvan villages (2010).

го рогатого скота.

Начиная с середины июля по конец августа - время сенокоса, на зиму для скота готовят большие запасы сена. В зимнее время мелкий рогатый скот находится в основном на подножном корму. Раньше перекочевки устраивали в летнее стойбище, затем осеннее, зимнее и весеннее. В настоящее время в связи с проблемой нехватки земли переезжают только в летние и зимние стойбища.

До наших дней соблюдаются скотоводческие поверья и запреты. Верят, что если некоторые виды скота приносят двойню, это чревато плохими последствиями для хозяев. Например, если кобылица или корова принесет двойню, это считается плохой приметой, поэтому одного из двойни убивают.

В отличие от основного места расселения китайских тувинцев, в последние годы разведение скота у тувинского населения в местностях Кок-Догай и Тамыкы связано с большими трудностями, так как здесь почти не осталось пастбищных угодий - земля засеяна овощными культурами, основным видом деятельности китайцев. Поэтому у этой части тувинцев скотоводство, как основная отрасль хозяйства, с каждым годом теряет свою актуальность. Тувинская молодежь вырастает без скотоводческих навыков. 
Охота. Охотничий промысел наряду со скотоводством у всех этнолокальных тувинских групп был одним из традиционных занятий, весьма значимой отраслью хозяйства. Китайские тувинцы промышляли белку, зайца, лису, волка, соболя, медведя, косулей, маралов, диких коз, рысей, а также птиц. Охотились верхом на коне, зимой - на лыжах-хаак, подбитых камусом из конской шкуры. Вместо палок использовали деревянный посох (тайак). В охоте применяли луки и стрелы, а затем ружья, использовали силки (шапкы), петли (тузак), самострелы (айа), загороди (кажаa). Каждый род имел свои родовые охотничьи угодья, на промысел уходили артелями. По мифологическим представлениям звери являются собственностью духа-хозяина Алтая Ак-огбена.

С начала 2000-х годов на территории Китайской Народной Республики был введен запрет на охоту и хранение огнестрельного оружия у местного населения. Не стал исключением и район проживания тувинцев, где запрещено охотиться и вырубать деревья. В связи с запретом в 2001 году у всего населения местные власти отобрали охотничьи принадлежности и ружья. Видимо, в связи с установившейся ситуацией запрета на охоту на территории КНР, у китайских тувинцев охотничий промысел уйдет в прошлое, забудутся навыки этого ремесла для последующих поколений. Кроме того, эти же места расселения тувинцев, Ак-Хаба, Ханас, Хом объявлены одной из заповедных зон и туристических мест Синьцзяна. Поэтому на сегодняшний день для топлива и строительства разрешено подбирать только упавшие деревья.

\section{Развитие этнотуризма}

На сегодняшний день Ханас, Хом и Ак-Хаба являются одним из популярных туристических регионов Китая, куда проложена современная автомобильная магистраль. Эти места стали излюбленным местом летнего отдыха многочисленных китайских туристов, куда порой в день прибывает до 20000 человек. Здесь для приезжих построены благоустроенные гостиницы с хорошим сервисом, кафетерии и бары.

В летнее время сюда приезжают люди разных национальностей из многих уголков Синьцзян-Уйгурского района, чтобы заработать туризмом, нередко выдавая себя тувинцами перед туристами. Также специально приезжают в Ханас и Хом китайцы-предприниматели, арендуя под гостиницы и кафе дома тувинцев.

Сами тувинцы названных сел также занимаются туристическим бизнесом. Хотя пункты общепита открывают лишь единицы некоторые из них продают национальные продукты питания: хойтпак, молочную араку, ааржы. Лишь немногие из тувинцев открыли чафан (кит. сл.) - заведение, где туристов знакомят с историей и культурой тувинского народа, показывают национальный танец 
бий, исполняют тувинские песни, играют на музыкальном инструменте шоор.

До 2014 г. частные компании, обслуживающие туристов, ежегодно выдавали местному населению (каждому члену семьи) денежные пособия, с тем условием, чтобы они не открывали в своих домах гостиницы для туристов. Считалось,

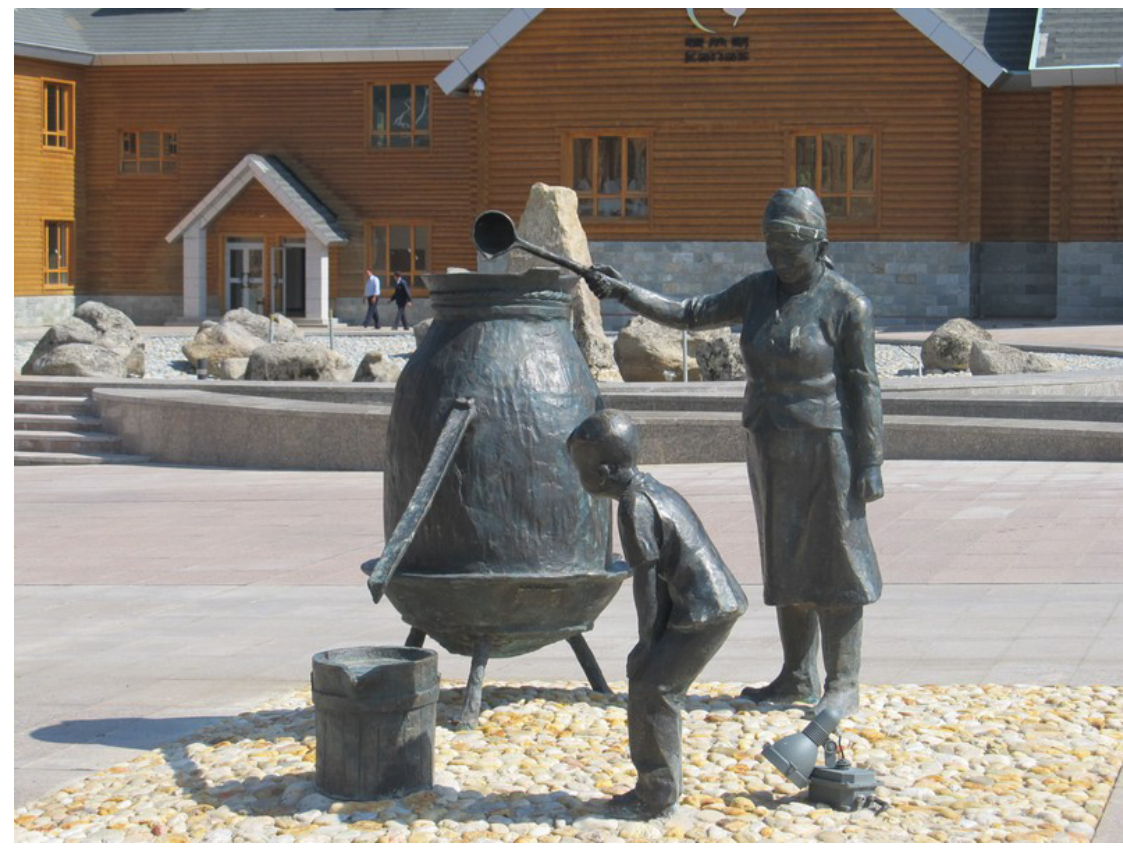

Фото 3. Скульптурное изображение, изображающая сцену изготовления молочной араги (2014 г.).

Photo 3. A sculptural scene of making araga, a strong milk-based spirit (2014) что, если же местные жители будут принимать путешественников у себя дома, это лишит компаний прибыли. Однако в связи с наплывом большого количества туристов, а также политикой местного начальства, в последние годы ситуация изменилась в лучшую сторону. Коренные жители теперь могут открывать в своих домах мини-гостиницы, точки питания, развлекательные центры. Поэтому везде можно наблюдать строительный бум.

При въезде в каждый населенный пункт путешественники оплачивают обязательный туристический налог. Местные власти часть доходов с него направляют на выплату аборигенному населению. Каждый житель Ак-Хабы получает 4000 юаней, Хома - 6000 юаней, Ханаса - 10000 юаней.

До 2013 г. туризм носил сезонный характер, основной поток туристов наблюдался только летом. Поэтому, чтобы привлечь путешественников в зимний сезон, по решению синьцзянских властей, было принято решение развивать существующую инфраструктуру и зимние виды туризма. С осени 2014 г. на территории Ханаса построены современные зимние горнолыжные комплексы, свидетельствующие о модернизации туристической индустрии.

Администрация сельской местности, где живут тувинцы, стремится поддерживать традиционную культуру и быт тувинцев. Это важно для привлечения туристов-ханьцев, которые платят за то, чтобы полюбоваться живописной природой и экзотикой, увидеть “вживую” скотоводов-кочевников как представителей малочисленного вымирающего народа, не имеющего своей национальной 
письменности, до сих пор живущего в необычных деревянных домах, пасущего скот и ездящего на лошадях. Нередко в средствах массовой информации Китая тувинцы представляются как дикий народ, живущий среди гор и тайги, не привыкший к благам цивилизации. Китайский антрополог Намкамидог считает, что уподобление тувинцев дикарям делается в целях рекламы, чтобы выгодным образом привлечь туристический поток в этот край (Namkamidog, 2009).

В настоящее время, с одной стороны, туризм помогает китайским тувинцам сохранить этническую идентичность и традиционную культуру, привлечь к себе внимание китайского правительства как уникального народа, отличающегося от монголов. Для большинства населения туризм является единственной возможностью заработать

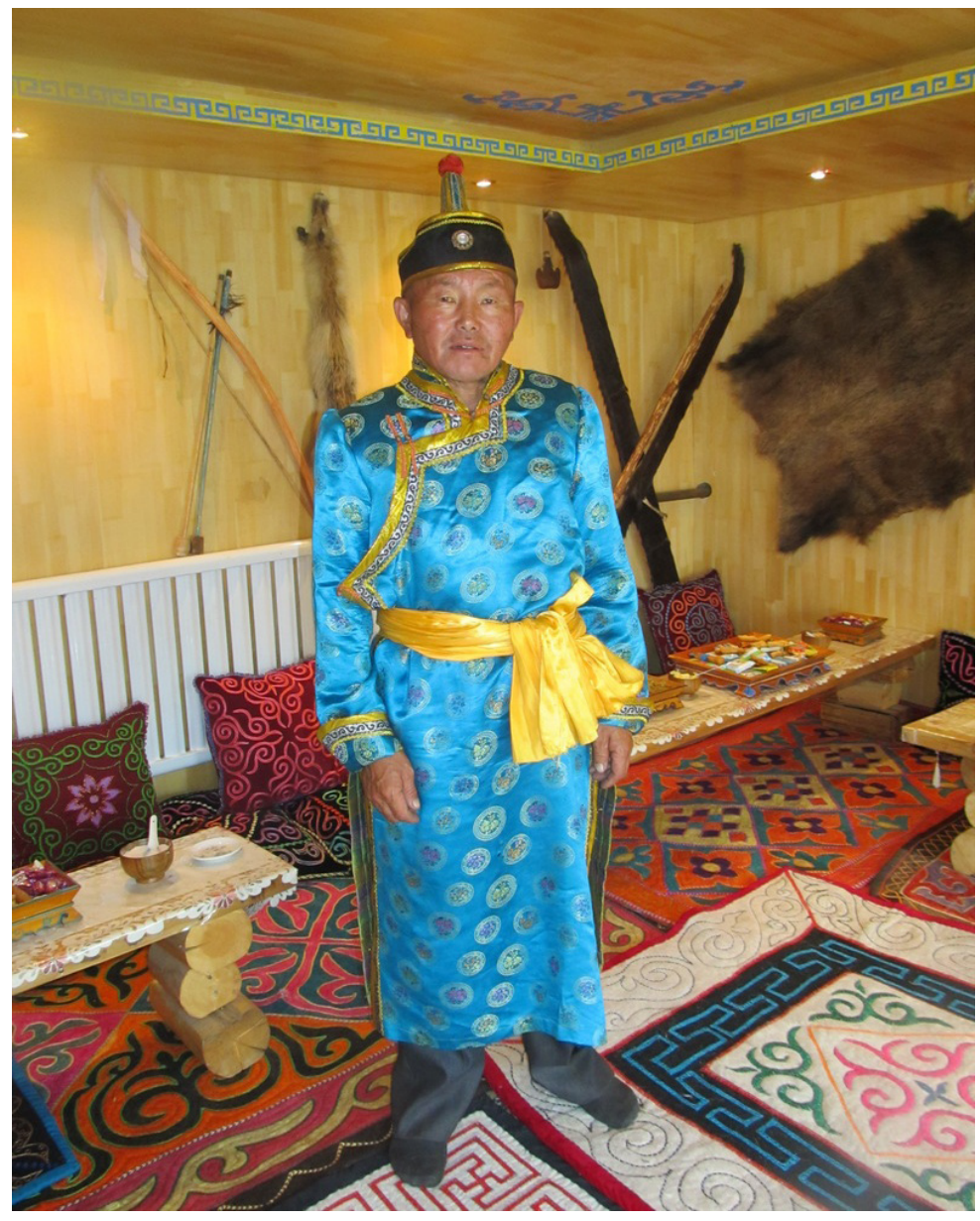

Фото 4. Тувинец, демонстрирующий туристам национальную одежду (2013 г.).

Photo 5. A Tuvan man shows items of ethnic clothing to tourists (2013). деньги. С другой стороны, некоторая часть тувинского населения обеспокоена тем, что в условиях туризма, где развиваются капиталистические денежные отношения, могут нарушиться традиционные устои народа, когда человек видит во всем только выгоду для себя, начинает заниматься зарабатыванием легких денег. Кроме этого, тревогу у коренного населения вызывает и то обстоятельство, что туристы не всегда соблюдают экологичное отношение к природе, у них нет благоговейного отношения к священным местам тувинцев.

В ноябре 2015 г. местные активисты обратились к музыкантам из Тувы обучить их искусству горлового пения и пригласили преподавателя-горловика. Приехал артист Национального оркестра Тувы Начын Шалык, который обучал желающих в течение месяца. Затем его сменил Радик Тюлюш, музыкант известной этногруппы “Хун-Хурту”, поработавший здесь в течение трех недель. Обучившиеся 
горловому пению молодые тувинцы открыли для туристов заведение чафан, где выступают перед ними, тем самым, дают отпор приезжим лже-тувинцам, которые на туристическом бизнесе зарабатывают деньги. В их репертуаре исполняются народные песни и кожамык российских тувинцев, не характерные для китайских тувинцев. Певцы утверждают, что мелодика своих народных песен не подходит для игры на национальных инструментах.

\section{Взгляды на будущее}

Китайских тувинцев, как признавались мне информанты, пугает перспектива утраты национальной культуры, родного языка, традиционной хозяйственной деятельности, экологичной системы природопользования. Причинами для тревоги стали все усиливающееся сокращение этноса, постепенное влияние иноэтничной культуры, нарастающая ассимиляция китайцев-ханьцев, устная форма родного языка и боязнь его постепенной утраты, будущая модернизация жизненных условий и в целом - потеря традиционной культуры.

В последние годы среди китайских тувинцев наблюдается небывалый рост национального самосознания. Теперь силами местных активистов планируется подготовительная работа по включению китайских тувинцев в список официально признанных национальностей Китая 57-ым народом. Наблюдается попытка реанимировать этноним тыва в пределах Китая в качестве самоназвания народа, чтобы другие этносы в отношении их пользовались этим этнонимом.

Таким образом, этнические тувинцы Китая, несмотря на то, что живут в отрыве от материнского этноса, невзирая на присутствие следующих негативных факторов: отсутствие национально-территориальной государственности; проживание на одной территории разных этносов, принадлежащих к разным культурам и конфессиям; официальное отнесение к монголам; численное преобладание иноязычного населения; пополнение словарной лексики за счет других языков; обучение в школах, сузах, вузах на других языках; устная форма родного языка; устная передача фольклора; отсутствие печатной литературы и СМИ на родном языке; отсутствие телепередач и радиовещания на родном языке; непрестижность тувинского языка для представителей других национальностей, до настоящего времени продолжают сохранять свою национальную идентичность, родной язык, традиционный фольклор, обычаи и обряды. Однако в условиях многоязычия в тувинской речи часто отмечаются случаи языковой интерференции, где обнаруживаются следы взаимодействий с языками соседних народов: казахов, монголов, китайцев. На это обстоятельство отрицательное влияние оказывает и отсутствие национальной письменности. Необходимо отметить и то, что живя в иноэтничном окружении, у тувинцев происходят процессы постепенной трансформации исконной культуры, усвоения некоторых 
мифологических представлений: в частности, китайских и монгольских. В фольклорной традиции суживаются рамки употребления сказок, загадок, пословиц и поговорок, мифологических рассказов.

\section{СПИСОК ЛИТЕРАТУРЫ}

Аблажей, Н. Н. (2007) С востока на восток: Российская эмиграция в Китае. Новосибирск: Изд-во СО РАН. 300 с.

Абрамзон, С. М. (1961) Киргизы Китайской Народной Республики // Известия Академии наук Киргизской ССР. Серия общественных наук. Том III, вып. 2. С. 119-132.

Бавуу-Сюрюн, М. В. (2011) Социолингвистические заметки о тувинцах Китая [Электронный ресурс] // Новые исследования Тувы. № 1.URL: https://nit.tuva.asia/nit/article/ view/445 (дата обращения: 09.01.2017).

Монгуш, М. В. (1997) Тувинцы в Китае (историко-этнографический очерк). Кызыл: Изд.-полигр. комплекс «Эне созу». 78 с.

Монгуш, М. В. (2002) Тувинцы Монголии и Китая: Этнодисперсные группы (История и современность). Новосибирск : Наука. 126 с.

Монгуш, М. В. (2010) Один народ: три судьбы. Тувинцы России, Монголии и Китая в сравнительном контексте. Осака: Национальный Музей Этнологии. 358 с.

Монгуш, М. В. (2012) У тувинцев Синьцзяна: двадцать лет спустя [Электронный ресурс] // Новые исследования Тувы. № 4. URL: https://nit.tuva.asia/nit/article/view/292 (дата обращения: 09.01.2017).

Октябрьская, И. В. (2009) Тувинцы // Историческая Энциклопедия Сибири : в 3 т. / гл. ред. В. А, Ламин. Новосибирск: Изд. дом «Историческое наследие Сибири». Т. III (С-Я). C. 313-314.

Тюхтенева, С. П. (2009) Земля. Вода. Хан Алтай. Этническая культура алтайцев в XX веке. Элиста: КалмГУ. 169 с.

Юша, Ж. М. (2009) Обрядовая поэзия тувинцев: структура и семантика. Новосибирск: Апельсин. 166 с.

Юша, Ж. М. (2013a) Современное бытование фольклорной традиции у тувинцев Китая // Сибирский филологический журнал. № 2. С. 56-62.

Юша, Ж. М. (2013b) Социолингвистическая ситуация у тувинцев Китая // Материалы Международной конференции «Тюркская руника». Кызыл. С. 157-161.

Юша, Ж. М. (2014а) Зарубежные тувинцы в объективе фотокамеры. Тувинцы Китая. Аннотированный фольклорно-этнографический фотоальбом. Новосибирск: Офсет. 160 с.

Юша, Ж. М. (2014b) Как встречают Новый год китайские тувинцы // Азия и Африка сегодня. № 12. С. 67-70. 
Юша, Ж. М. (2014c) Шоор в традиционной культуре тувинцев Китая [Электронный ресурс] // Новые исследования Тувы. № 1. URL: https://nit.tuva.asia/nit/article/view/179 (дата обращения: 09.01.2017).

Юша, Ж. М. (2016а) Тувинцы Китая и Монголии: современное состояние фольклорной традиции // Сибирский филологический журнал. № 2. С. 5-10.

Юша, Ж. М. (2016b) Современное бытование несказочной прозы у тувинцев Китая // Языки и фольклор коренных народов Сибири. № 4. С. 126-131.

Geng Shimin (2005) Materials on Tuvinian language of China // Алтайские языки и восточная филология : сборник статей. М.: Восточная лит-ра РАН. С. 409-503.

Namkamidog (2009). Xinjiang Tuwaren shenuiwenhua tianyediaocha yu yanjiu. Beijing. (На кит. яз.).

Song Zhengchun (2016) Tuwa yu he Tuwaren de dou yu shenghuo (Tuva Language and the multi-lingual life of the Tuvinian people in China). Beijing. (На кит. яз.).

Mawkanuli, T. (2005) Jungar Tuvan Texts. Indiana University Bloomington Research Institute for Inner Asian Studies, Bloomington.

Yusha, Zh. (2014) Cin ve Mogolistan'daki Tuvalarin Cocuk edebiyatinda sorunlari // I. Uluslararasi Cocuk ve Genclik edebiyati sempozyumu bildirileri. 24-25 Ekim 2014, MaltepeIstanbul. S. 65-67.

Yusha, Zh. (2016a) Let him be gray-headed! Childhood in the modern culture of Chinese Tuvinians // Science first hand. № 1. P. 118-127.

Yusha, Zh. (2016b) Cin Tuvalarinin Folkloru (Folklore of Tuvininans of China) // Belleten. Turk Dili Arastirmalari Yilligi. Cilt 61. № 2. S. 261-266.

Дата поступления: 15.01.2017 2.

\section{REFERENCES}

Ablazhei, N. N. (2007) S vostoka na vostok: Rossiiskaia emigratsiia v Kitae. Novosibirsk: Izd-vo SO RAN. 300 p. (In Russ.)

Abramzon, S. M. (1961) Kirgizy Kitaiskoi Narodnoi Respubliki. Izvestiia Akademii nauk Kirgizskoi SSR. Seriia obshchestvennykh nauk. Vol. III, Iss. 2. Pp. 119-132. (In Russ.)

Bavuu-Siuriun, M. V. (2011) Sociolinguistic notes about the Tuvans in China. The New Research of Tuva, no. 1 [online] Available at: https://nit.tuva.asia/nit/article/view/445 (access date: 09.01.2017). (In Russ.)

Mongush, M. V. (1997) Tuvintsy v Kitae (istoriko-etnograficheskii ocherk). Kyzyl, Izd.-poligr. kompleks «Ene sozu». 78 p. (In Russ.)

Mongush, M. V. (2002) Tuvintsy Mongolii i Kitaia: Etnodispersnye gruppy (Istoriia $i$ sovremennost'). Novosibirsk, Nauka. 126 p. (In Russ.) 
Mongush, M.V.(2010) Odin narod: tri sud'by. Tuvintsy Rossii, Mongolii i Kitaia v sravnitel'nom kontekste. Osaka, Natsional'nyi Muzei Etnologii. 358 p. (In Russ.)

Mongush, M. V. (2012) At Xinjian Tuvans: twenty years later. The New Research of Tuva, no. 4 [online] Available at: https://nit.tuva.asia/nit/article/view/292 (access date: 09.01.2017). (In Russ.)

Oktiabr'skaia, I. V. (2009) Tuvintsy. In: Istoricheskaia Entsiklopediia Sibiri : in 3 vols, ed. by V. A, Lamin. Novosibirsk, Izd. dom «Istoricheskoe nasledie Sibiri». Vol. III (S-Ya). Pp. 313314. (In Russ.)

Tiukhteneva, S. P. (2009) Zemlia. Voda. Khan Altai. Etnicheskaia kul'tura altaitsev v XX veke. Elista, KalmGU. 169 p. (In Russ.)

Yusha, Zh. M. (2009) Obriadovaia poeziia tuvintsev: struktura i semantika. Novosibirsk, Apel'sin Publ. 166 p. (In Russ.)

Yusha, Zh. M. (2013a) Sovremennoe bytovanie fol'klornoi traditsii u tuvintsev Kitaia. Sibirskii filologicheskii zhurnal, no. 2, pp. 56-62. (In Russ.)

Yusha, Zh. M. (2013b) Sotsiolingvisticheskaia situatsiia u tuvintsev Kitaia. In: Materialy Mezhdunarodnoi konferentsii «Tiurkskaia runika». Kyzyl. Pp. 157-161. (In Russ.)

Yusha, Zh. M. (2014a) Zarubezhnye tuvintsy $v$ ob'ektive fotokamery. Tuvintsy Kitaia. Annotirovannyi fol'klorno-etnograficheskii fotoal'bom. Novosibirsk, Ofset Publ. 160 p. (In Russ.)

Yusha, Zh. M. (2014b) Kak vstrechaiut Novyi god kitaiskie tuvintsy. Aziia i Afrika segodnia, no. 12, pp. 67-70. (In Russ.)

Yusha, Zh. M. (2014c) Shoor in the traditional culture of Tuvans in China. The New Research of Tuva, no. 1 [online] Available at: https://nit.tuva.asia/nit/article/view/179 (access date: 09.01.2017). (In Russ.)

Yusha, Zh. M. (2016a) Tuvintsy Kitaia i Mongolii: sovremennoe sostoianie fol'klornoi traditsii. Sibirskii filologicheskii zhurnal, no. 2, pp. 5-10. (In Russ.)

Yusha, Zh. M. (2016b) Sovremennoe bytovanie neskazochnoi prozy u tuvintsev Kitaia. Iazyki i fol'klor korennykh narodov Sibiri, no. 4, pp. 126-131. (In Russ.)

Geng Shimin (2005) Materials on Tuvinian language of China. In: Altaiskie iazyki $i$ vostochnaia filologiia : sbornik statei. Moscow, Vostochnaia literatura RAN. Pp. 409-503. (In Russ.)

Namkamidog (2009). Xinjiang Tuwaren shenuiwenhua tianyediaocha yu yanjiu. Beijing. (In Chinese).

Song Zhengchun (2016) Tuwa yu he Tuwaren de dou yu shenghuo (Tuva Language and the multi-lingual life of the Tuvinian people in China). Beijing. (In Chinese).

Mawkanuli, T. (2005) Jungar Tuvan Texts. Indiana University Bloomington Research Institute for Inner Asian Studies, Bloomington. 
Yusha, Zh. (2014) Cin ve Mogolistan'daki Tuvalarin Cocuk edebiyatinda sorunlari. In: I.Uluslararasi Cocuk ve Genclik edebiyati sempozyumu bildirileri. 24-25 Ekim 2014, MaltepeIstanbul. S. 65-67. (In Turk.)

Yusha, Zh. (2016a) Let him be gray-headed! Childhood in the modern culture of Chinese Tuvinians. Science first hand, no. 1, pp. 118-127.

Yusha, Zh. (2016b) Cin Tuvalarinin Folkloru (Folklore of Tuvininans of China). Belleten. Turk Dili Arastirmalari Yilligi. Cilt 61. № 2. S. 261-266. (In Turk.)

Submission date: 15.01.2017,

\section{Для цзитирования:}

Юша Ж. М. Тувинцы Китая в XXI веке: вехи истории и современное состояние [Электронный ресурс] // Новые исследования Тувы. 2017. № 1. URL: https://nit.tuva.asia/nit/ article/view/699 (дата обращения: дд.мм.гг.). DOI: 10.25178/nit.2017.1.6

\section{For citation:}

Yusha Zh. M. Tuvans in 21st century China: history and contemporary situation [online] New Research of Tuva. 2007. No.1. URL: https://nit.tuva.asia/nit/article/view/699 (access date: dd.mm.yy.). DOI: 10.25178/nit.2017.1.6 